\title{
ISLAM WAŞATIYYAH: REFLEKSI ANTARA ISLAM MODERN DAN UPAYA MODERASI ISLAM
}

\section{Mohamad Deny Irawan}

Universitas Islam Negeri (UIN) Syarif Hidayatullah Jakarta

Email: hans_deny@yahoo.co.id

\begin{abstract}
Discourse on moderate Islam in the academic world began to stick to the surface. How come? the emerging tensions in the Middle East, the stagnantization of the development of Islam in Africa to Islamophobia in Europe play an important role in the emergence of moderate Islamic discourse offered by Muslims in Indonesia. Islam in Indonesia does have a different tendency than the Muslim community in some countries. Azyumardi Azra in a lecture session repeatedly expressed the importance of developing a modeled musical style in Indonesia. As a country with the largest Muslim majority in the world, Indonesia also demonstrates an important role in making the image of Islam slightly shifted from a set of sentiments of violence-endowed violence to Islam that has a peaceful love outlook but remains within the framework of Islam.

Diskursus tentang Islam moderat di dunia akademik mulai mencuat ke permukaan. bagaimana tidak? ketegangan yang muncul di Timur tengah, stagnanisasi perkembangan islam di Afrika hingga islamophobia di Eropa sangat berperan penting dalam kemunculan wacana islam moderat yang ditawarkan muslim di Indonesia. Islam di Indonesia memang memiliki kecendrungan berbeda dibandingan komunitas muslim di beberapa negara. Azyumardi Azra dalam sesi perkuliahan berulang kali mengungkapkan pentingnya pengembangan corak muslim yang diperagakan di Indonesia. Sebagai negara dengan mayoritas muslim terbesar di dunia, Indonesia juga memeragakan peranan penting dalam membuat citra Islam sedikit bergeser dari setnimen keekrasan berujung kekerasan ke Islam yang memiliki cara pandang cinta damai namun tetap berada dalam bingkai Islam.
\end{abstract}

Keywords: Modernism, Islam Wasatiyyah, Moderat Islam

TAJDID Vol. XVI, No. 2, Juni - Desember 2017|111 


\section{Pendahuluan}

Pemahaman tentang Islam moderat juga tidak dapat dilepaskan dari periodesasi pemikiran di dunia, seperti: zaman klasik, zaman modern, post-modern dan lain sebagainya. Yang menjadi pertanyaan adalah apakah pola Islam moderat diwarnai oleh pola pikir modern atau postmodern? pengaruh apa yang dibawa oleh modernisme terhadap Islam? apa yang mendasari tata cara berpikir modern? dan bagaimana sebaiknya muslim menyikapi wacana Islam moderat? berikut penjabarannya.

Sebelum membahasa tentang modern dan modernisme secara mendalam, ada baiknya peninjauan kembali makna modern dan modernisme perlu dilakukan. Dalam Encyclopedia of philosophy, modernisme diartikan sebagai pergerakan pemikiran yang dilakukan oleh katolik untuk mengkritik bible. ${ }^{1}$ Filsafat modern terbentuk sebagai awal dari renaissance, yang sengaja dibentuk sebagai pondasi ilmu pengetahuan.

Menurut F. Budi Hardiman, ${ }^{2}$ pemahaman tentang modern dapat dimaknai dalam 2 hal, yaitu: modern sebagai bagian dari periodesasi pemikiran filsafat dan modern sebagai kesadaran menuju pada sesuatu yang kebaruan. Selain itu, dalam bingkai filsafat, kemunculan modern berangkat dari pemberontakan intelektual yang jika ditelusuri lebih mendalam memiliki kaitan erat dengan Renaissance di Prancis serta gerakan humanisme. ${ }^{3}$ Meski demikian, pola kebaruan yang terdapat dalam pola modernisme tidak saja selalu berbentuk fisik sehingga aspek non fisik juga dibutuhkan. Di kalangan modernis, modern disamakan dengan tajdid yang berarti menghidupkan kembali apa yang telah dilupakan/ditinggalkan dari ajaran-ajaran agama guna mereformasi kehidupan kaum muslim secara umum ke arah yanglebih baik. ${ }^{4}$ Secara ringkas, Amal Fathullah Zarkasyi menyebut modernisasi

${ }^{1}$ Donald M. Borchert dkk, Encyclopedia Of Philosophy (Farmington Hills: Thomson Gale, 2006), 316.

2 F. Budi Hardiman, Filsafat Modern: Dari Machiavelli samapai Nietasche (Jakarta: Gramedia Pustaka Utama, 2007), 2-3.

${ }^{3}$ F. Budi Hardiman, Filsafat Modern: Dari Machiavelli samapai Nietasche5-12

4 Amal Fathullah Zarkasyi, "Tajdid dan Modernisasi Pemikiran Islam",Tsaqafah vol. 9, No. 2 (2013) : 399.

112 | TAJDID Vol. XVI, No. 2, Juni - Desember 2017 
berarti mengembalikan kembali sesuatu yang sudah hilang dan menerapkannya di kehidupan. ${ }^{5}$ meski demikian, Amal menolak ide yang menyebut modernisasi adalah tajdid melainkan lebih memaknainya sebagai taghrïb (westernisasi). ${ }^{6}$

Fazlur Rahman dalam karyanya „Islam and Modernity". Setidaknya ada 3 pembahasan terkait modernitas yang coba dijabarkan oleh Fazlur Rahman tersebut, yaitu: khazanah keislaman (heritage), Pendidikan Islam, peluang dan tantangan umat muslim di masa mendatang. Bagi Fazlur Rahman, ${ }^{7}$ khazanah (heritage) yang dimiliki Islam sangat bermanfaat untuk kembali dimunculkan dengan menjadikan Al-Qur an dan Sunnah sebagai dua komponen penting pedoman modernisme di dunia Islam. Hamid Fahmy Zarkasyi $^{8}$ menolak ide modernitas ditawarkan Fazlur Rahman serta menganggap jika modernisasi yang diterapkan merupakan bagian dari pola liberalisasi keagamaan. Selain modernisasi, Hamid juga menyebut upaya tipologi Islam seperti tradisionalis, modernis, fundamentalis dan sekularis juga menjadi bagian dari proyek westernisasi. ${ }^{9}$

\footnotetext{
5 Amal Fathullah Zarkasyi, “Tajdid dan Modernisasi Pemikiran Islam” : 400.

${ }^{6}$ Dalam penjelasannya, Amal menjabarkan pola modernisasi yang terjadi di dunia islam seperti modernisasi menurut Syed Ahmad Khan (1817-1898), Modernisasi sir Muhammad Iqbal, Modernisasi Qasim Amin, modernisasi Ali Abd al- Raziq. Amal Fathullah Zarkasyi, "Tajdid dan Modernisasi Pemikiran Islam" : 408-416.

7 Fazlur Rahman membagi penjelasannya tentang khazanah keilmuan dalam islam dengan menitikberatkan pada sumber yang bersal dari Al-Quran dan pesan kenabian, perkembangan disiplin-disiplin keilmuan dalam islam, perubahan institusi pendidikan di abad pertengahan islam, Pendidikan di era pertengahan islam dan pola pendidikan islam yang terjadi di Paksitan. Fazlur Rahman, Islam and modernity: transformation of an Intellectual tradition (London: The University of Chicago press, 1919), 13-42.

8 Hamid menilai kalangan modernis merupakan kelompok yang menginginkan agar dunia islam menjadi bagian dari moderniatas global. Mereka ingin memodernisir islam agar sejalan dengan zaman. Hamid Fahmy Zarkasyi, "Liberalisasi pemikiran Islam: Gerakan bersama Misionaris, Kolonialis dan Orientalis" Tsaqafah vol. 4, No. 2 (2009) : 245.

${ }^{9}$ Hamid Fahmy Zarkasyi, "Liberalisasi pemikiran Islam: Gerakan bersama Misionaris, Kolonialis dan Orientalis" : 245-246.
}

TAJDID Vol. XVI, No. 2, Juni - Desember $2017 \mid 113$ 
Ada beberapa tokoh yang menjadi „penopang ${ }^{e e}$ bangunan filsafat modernisme, diantaranya: periode modern (Nicolo Machiavelli, Giordano Bruno, Sir Francis Bacon); Tokoh Rasionalisme (Rene Descartes, Baruch Spinoza, Leibniz, Blaise Pascal); Tokoh empirisme (Thomas Hobbes, John Locke, George Barkeley, David Hume); Tokoh penggabung antara rasionalisme dan empirisme (Imanuel Kant); Tokoh Idealisme (Johan Gottlieb Fichte, Friedrich wilhelm joseph schelling dan Georg Willhelm Friedrich Hegel); Tokoh Positivisme (Auguste Comte); serta tokoh „pembunuhe modernisme (Nietzsche). Nama terakhir sering dikaitkan sebagai pembangkit aliran filsafat post-modernisme yang berlaku setelah pola modern.

\begin{tabular}{|c|c|c|c|}
\hline NO & PAHAM & TOKOH & CORAK PEMIKIRAN \\
\hline 1 & $\begin{array}{l}\text { Periode Awal } \\
\text { Modernisme }\end{array}$ & $\begin{array}{l}\text { - Nicolo Machiavelli } \\
\text { - Giordano Bruno } \\
\text { - Sir Francis Bacon }\end{array}$ & $\begin{array}{l}\text { - Anti-moralitas; Anti } \\
\text { otoritas dan pendapat } \\
\text { yang bertentangan } \\
\text { dengan gereja; } \\
\text { - Antroposentrisme } \\
\text { - Metode Deduksi }\end{array}$ \\
\hline 2 & Rasionalisme & $\begin{array}{l}\text { - Rene Descartes } \\
\text { - Leibniz } \\
\text { - Pascal } \\
\text { - Thomas Hobbes } \\
\text { - John Locke }\end{array}$ & $\begin{array}{l}\text { - Rasio lebih utama } \\
\text { dibanding Empirisme; } \\
\text { - Penggunaan metode } \\
\text { geometris (more } \\
\text { geometrico demonstrata); } \\
\text { - Teori monad; } \\
\text { - Ilmu pengetahuan } \\
\text { berlandaskan pengalaman } \\
\text { - Anti-spiritualitas }\end{array}$ \\
\hline 3 & Empirisme10 & $\begin{array}{l}\text { George Barkeley } \\
\text { David Hume }\end{array}$ & $\begin{array}{l}\text { - Humanisme } \\
\text { - Sekuleristik } \\
\text { - Materialisme } \\
\text { - Agama sebagai kontrol } \\
\text { sosial11 } \\
\text { - Esse est perceived } \\
\text { - Antroposentris } \\
\text { - Deisme (agama natural/ }\end{array}$ \\
\hline
\end{tabular}

${ }^{10}$ F. Budi Hardiman, Filsafat Modern: Dari Machiavelli samapai Nietzsche :65-93.

${ }^{11}$ F. Budi Hardiman, Filsafat Modern: Dari Machiavelli samapai Nietzsche, 72.

114 | TAJDID vol. XVI, No. 2, Juni - Desember 2017 


\begin{tabular}{|c|c|c|c|}
\hline & & & $\begin{array}{l}\text { agama akal) } \\
\text { - Realisme empirikal }\end{array}$ \\
\hline 4 & Kritisisme12 & Immanuel Kant & $\begin{array}{l}\text { - Idealisme transendental } \\
\text { - Mode of thought in } \\
\text { methapysic paradigm } \\
\text { - tiga tahap pemikiran } \\
\text { manusia: teologis, } \\
\text { metafisis dan positif. }\end{array}$ \\
\hline 5 & Positivisme13 & Auguste Comte & $\begin{array}{l}\text { - Menolak metafisik dan } \\
\text { teologik }\end{array}$ \\
\hline 6 & $\begin{array}{l}\text { Akhir } \\
\text { Modernisme }\end{array}$ & $\begin{array}{l}\text { Friedrich } \\
\text { Nietchze }\end{array}$ & $\begin{array}{l}\text { - Anti otoritas } \\
\text { - Ateistik } \\
\text { - Nihilisme }\end{array}$ \\
\hline
\end{tabular}

\section{Filsafat Nietzsche: Akhir Modernisme}

Postmodernisme merupakan sebuah gerakan kekinian (contemporary movement) yang kuat dan menjadi trend. ${ }^{14}$ Kemunculan postmodernisme ini sebenarnya tidaklah secara tiba-tiba, tapi dipengaruhi oleh pemikiran para filosof seperti Nietzsche, Husserl, Wittgenstein serta para pemikir struktulisme seperti Lacan dan Foucault. Nietzsche sendiri adalah filosof penting bagi kemunculan

12 Kritisisme merupakan filsafat yang memulai perjalanannya dengan terlebih dahulu menyelidiki kemampuan rasio dan batas-batasnya. Kant memulainya dengan mengritik rasio murni, rasio praktis dan kritik atas daya pertimbangan. Muhammad Muslih, Filsafat ilmu: Kajian atas asumsi dasar paradigma dan kerangka teori ilmu pengetahuan (Yogyakarta: Penerbit Belukar, 2006) cet. ke-3, 60-61.

13 Filsafat positivisme merupakan filafat yang menolak metafisik dan teologik. Comte mendudukkan metafisik dan teologik sebagai sesuatu yang primitif. Noeng Muhadjir, Metode Penelitian Kualitatif (Yogyakarta: Rake Sarasin, 2000): 12 .

14 Ernest Gellner, Postmodernism, Reason \& Religion (London: Routledge, 1992), 22.

TAJDID Vol. XVI, No. 2, Juni - Desember 2017|115 
post-modernisme. ${ }^{15}$ Walaupun sebenarnya dia hidup pada abad ke19 , namun pengaruh pemikirannya melebihi zamannya. ${ }^{16}$

Nietzsche beranggapan bahwa ia menulis untuk khalayak di masa depan yang lebih apresiatif. Diantara pemikiran-pemikiran Nietzsche yang sangat mempengaruhi para pemikir postmodernisme diantaranya pemajemukan kesadaran modern melalui cerita rakyat, relativitas nilai, makna dan tatanan nilai yang tidak obyektif dan anti kemapanan. ${ }^{17}$

Nietzsche mengenalkan metode genealogi melalui karyanya Genealogy of Moral. Dalam buku ini ditulis bahwa kita tidak kenal dengan diri kita, kita manusia yang berpengetahuan dan berakal cukup. ${ }^{18}$ Tema yang diusung oleh Nietszche adalah bahwa manusia yang mengalami kegagalan, itu dikarenakan kurangnya keberanian, untuk menyingkapkan apa yang berada di dalam fondasi eksistensi manusia, khususnya moralitas, walaupun mungkin manusia memandang diri mereka memiliki informasi luas, berpengalaman dan berpengetahuan. ${ }^{19}$

Di sini Nietszche megungkapkan fakta bahwa manusia telah menekan dan bersembunyi dari diri mereka sendiri. Nietszche mencoba melakukan penyembuhan ketika manusia tertipu oleh diri

15 Nietzsche bisa dipandang sebagai perintis penting dalam kebanyakan pemikiran postmodern ( $\mathrm{He}$ can be seen as the major precursor of much postmodern thought). Patricia Waugh, Postmodernism (USA: Routledge, Chapman and Hall, 1992), 4. Stuart SIM, The Routledge Companion to Postmodernism (London: Routledge, 2001), 3.

16 Post-modern beranggapan bahwa yang ada hanyalah interpretasiinterpretasi. Robert C. Salomon dan Kathleen M. Higgins, Sejarah Filsafat, terj. Saut Pasaribu (Yogyakarta: Bentang Budaya, 2003) cet ke-2, 541.

${ }^{17}$ Misnal Munir, Aliran-Aliran Utama Filsafat Barat Kontemporer (Yogyakarta: Penerbit Lima, 2008), 129. Robert C. Salomon dan Kathleen M. Higgins, Sejarah Filsafat, 426.

${ }_{18}$ We are unknown to ourselves, we man of knowledge and with good reason. John K. Roth, "Persoalan-Persoalan filsafat agama", Kajian Pemikiran 9 Tokoh dalam Sejarah Filsafat dan Teologi, terj. Ali Noer Zaman (Yogyakarta: Pustaka Pelajar, 2003), 299.

19 John K. Roth, "Persoalan-Persoalan filsafat agama”, Kajian Pemikiran 9 Tokob dalam Sejarah Filsafat dan Teologi, 229.

116 | TAJDID Vol. XVI, No. 2, Juni - Desember 2017 
mereka sendiri. ${ }^{20}$ Dan dia juga mencoba menjawab pertanyaanpertanyaan yang ia ajukan untuk dirinya sendiri melalui dua pendekatan, yaitu; pertama, menjelaskan pemahamannya tentang asal-usul dan sifat perbedaan antara baik dan buruk (good and bad) dan antara baik dan jahat (good and evi), kedua, menyingkapkan klaimnya bahwa kebutuhan kita adalah untuk bergerak melalui kebaikan dan kejahatan. ${ }^{21}$

Yang menjadikan keberatan Nietzsche terhadap agama Kristen adalah keberatan terhadap ajaran yang menyebabkan diterimanya apa yang ia sebut moralitas budak. Nietzsche tidak tertarik terhadap kebenaran metafisis atau agama Kristen, ${ }^{22}$ ataupun agama apa saja; dengan yakin bahwa tidak ada agama yang sungguh-sungguh benar, ia menimbang semua agama seluruhnya dengan efek sosialnya. Ia sepakat dengan filosof-filosof yang menolak penyerahan diri kepada apa yang diduga sebagai kehendak Tuhan, tetapi ia menggantinya dengan kehendak seniman-tiran yang membumi. Penyerahan adalah baik, kecuali bagi manusiamanusia super, tetapi bukan kepada Tuhan Kristiani. Karena agama Kristen adalah kebohongan yang paling fatal dan paling menawan yang pernah ada. ${ }^{23}$

Dalam filsafat Nietzsche juga disebutkan bahwa moralitas ada dua, yaitu moralitas tuan dan moralitas budak. Moralitas tuan pada awalnya adalah moralitas yang baik. Yang menganut moralitas tuan adalah kaum yang kuat sedangkan yang menganut moralitas budak adalah kaum yang lemah. Pada awalnya kaum kuat berada di atas. Namun, semakin lama mereka semakin menerima pula moralitas budak. Sehingga kaum yang kuat semakin berkurang jumlahnya. Akibatnya kaum yang lemah menjadi semakin banyak dan pada

${ }^{20}$ John K. Roth, "Persoalan-Persoalan filsafat agama", Kajian Pemikiran 9 Tokob dalam Sejarah Filsafat dan Teologi, 229.

${ }^{21}$ John K. Roth, "Persoalan-Persoalan filsafat agama", Kajian Pemikiran 9 Tokob dalam Sejarah Filsafat dan Teologi, 230.

22 Nietsczhe memandang bahwa penganut Kristen (Crhistianity) merupakan fase akhir yang paling berbahaya atau merugikan (the latest and most pernicious stage). Dave Robinson, Nietasche and Postmodernism (London: Cox \& Wyman Ltd., 1999), 10.

${ }^{23}$ Bertrand Russel, Sejarah Filsafat Barat, terj. Sigit Jatmiko dkk (Yogyakarta: Pustaka Pelajar, 2007) cet. ke-3 995-996.

TAJDID Vol. XVI, No. 2, Juni - Desember $2017 \mid 117$ 
akhirnya mereka yang lemah dan tertindas ini membalikkan keadaan. Sehingga moralitas tuan yang tadinya dianggap moralitas yang baik berganti menjadi moralitas yang buruk, begitu pula sebaliknya. $^{24}$

Pengertian baik mempunyai pengertian yang sangat berlainan. Pengertian baik bagi majikan (tuan) adalah perasaan jiwa yang tinggi, yang bangga dan megah. Sedangkan baik bagi budak adalah apa yang damai, yang tidak merugikan dan yang menaruh belas kasihan. Dan yang disebut jahat bagi majikan (tuan) adalah apa yang berlaku umum, yang biasa, yang tak bernilai. sedangkan jahat bagi budak adalah segala sesuatu yang menonjol melebihi kawanan seluruhnya, jadi yang luar biasa, yang tidak dapat diperhitungkan dan yang berbahaya. ${ }^{25}$

Berbeda dengan moralitas orang Athena kuno, yaitu moralitas heroisme dan penguasa, moralitas Kristen telah menjadikan orang yang lemah dan biasa sebagai contoh moral. Yang paling buruk, pandangan dunia moral Kristen telah mendorong orang untuk menganggap kehidupan alam akhirat sebagai sesuatu yang lebih penting daripada kehidupan di dunia ini. Bukannya mendorong pemajuan diri dalam istilah-istilah duniawi, visi moral Kristen malah menekankan pemantangan pada hal-hal pementingan diri tersebut. Dalam hal ini, Nietzsche memprotes, adalah perbuatan bodoh, dan itu akan mengakibatkan (dan sudah mengakibatkan) kehancuran umat manusia. ${ }^{26}$

Manusia luhur menurut Nietzsche pada dasarnya adalah jelmaan kehendak untuk berkuasa. ${ }^{27}$ Akan tetapi dalam kehendaknya untuk berkuasa, manusia tidak boleh melawan realitas. Jika manusia melawan realitas maka kehidupannya akan menderita karena terkadang manusia memiliki keinginan yang

${ }^{24}$ John K. Roth, "Persoalan-Persoalan filsafat agama", Kajian Pemikiran 9 Tokob dalam Sejarah Filsafat dan Teologi, 300.

${ }^{25}$ Harun Hadiwijono, Sari Sejarah Filsafat Barat 2 (Yogyakarta: Kanisius, 1980), 128.

${ }^{26}$ Robert C. Salomon dan Kathleen M. Higgins, Sejarah Filsafat, 424.

27 Menurutnya manusia luhur bukanlah sebagai tipe universal, melainkan sebagai aristokrat yang memerintah. Bertrand Russel, Sejarah Filsafat Barat, 996997.

118 | TAJDID Vol. XVI, No. 2, Juni - Desember 2017 
berlawanan dengan realitas. Apabila keinginan itu terus dipaksakan, maka manusia harus melawan realitas, sedangkan menurut Nietzsche yang terjadi tidak dapat dihindari. Sehingga untuk melawan realitas adalah sia-sia. Sehingga lebih baik manusia menerima hidup apa adanya dengan lapang dada.

Selain itu manusia harus membuat hukum untuk dirinya sendiri, ini bertujuan agar manusia dapat menjadi majikan atas dirinya sendiri. Dengan membuat hukum untuk dirinya sendiri, manusia dapat mengendalikan dirinya dalam menghadapi kehidupan. Dengan dua prinsip tersebut maka manusia dapat hidup menjadi manusia yang kuat dalam menghadapi hidup yang merupakan penderitaan.

Nietzsche juga memiliki pemikiran tentang si manusia super, Manusia yang ideal adalah manusia atas atau superman (Ubermensch). ${ }^{28}$ kekuatan dan pengulangan abadi. Manusia super menurut Nietzsche adalah tingkat tertinggi dari kemanusiaan. Namun, tingkat ini hanya bisa dicapai ketika massa dikorbankan kepada kaum elite. Hanya siapa yang dapat berkorbanlah (menderita) yang dapat berpikir, dan hanya pemikirlah yang sungguh-sungguh dapat menjadi penguasa. ${ }^{29}$ Kekuatan menurut Nietzsche adalah hukum dari suatu masyarakat yang "sehat ${ }^{\text {ee }}$. Masyarakat dianggap sakit bila ia menyerah pada paham „martabat manusia" dan „martabat kerja". Sedangkan pengulangan abadi menurut Nietzsche adalah mengenai kehidupan ini yang sebenarnya terus berulang dari masa ke masa. ${ }^{30}$

Ketika Nietzsche sedang melakukan studi terhadap gagasangagasan Yunani kuno, ia menyimpulkan bahwa kekuatan yg menjadi pendorong di dalam peradaban mereka semata-mata

${ }^{28}$ Harun Hadiwijono, Sari Sejarah Filsafat Barat 2, 129. Seorang manusia yang mengembangkan potensinya secara maksimal akan menjadi manusia super. Dan karena alasan itulah dia menciptakan istilah superman, yang kini menjadi kata yang dikenal di seluruh dunia. Bryan Magee, The Story Of Philosophy, terj. Marcus Widodo dan Hardono Hadi (Yogyakarta: Kanisius, 2008), 174.

${ }^{29}$ Harun Hadiwijono, Sari Sejarah Filsafat Barat 2, 129.

30 Menurutnya, manusia hidup bukanlah untuk kesenangan, dan itu hanya orang Inggris yang melakukannya. Robert C. Salomon dan Kathleen M. Higgins, Sejarah Filsafat, 418.

TAJDID Vol. XVI, No. 2, Juni - Desember 2017 |119 
adalah bagaimana mencari kekuasaan, dan bukan untuk mencari sesuatu yang lebih berguna atau yang memberikan manfaat segera.Nietzsche menyimpulkan bahwa kemanusiaan didorong oleh suatu kehendak untuk berkuasa (Will For Power). ${ }^{31}$

Menurutnya, Pikiran merupakan alat mengendalikan insting (kehendak untuk hidup dan berkuasa), dan pengetahuan memiliki nilai jika dapat meningkatkan dan mempertahankan kehidupan. ${ }^{32}$ Seperti halnya Schopenhourer, Nietzsche bersikukuh bahwa manusia dan makhluk lainnya yang ada di alam pada dasarnya penuh kehendak, ${ }^{33}$ namun Nietzsche melangkah lebih jauh dan menyarankan bahwa kita (dan semua makhluk alam) memiliki kehendak untuk berkuasa, ${ }^{34}$ yang didorong oleh keinginan untuk memperbesar vitalitas dan kekuasaan kita. Menurut Nietzsche, bertahan hidup adalah bersifat sekunder. Dia menentang pesimisme Schopenhourer tentang makna kehidupan, Nietzsche menegaskan bahwa vitalitas itu sendirilah arti kehidupan, dan penerimaan kehidupan haruslah menjadi kesimpulan filsafat, bukan penolakannya, bukan pula pengunduran dari dirinya. ${ }^{35}$

Keyakinan yang mendasari pemikiran Nietzsche adalah bahwa Tuhan telah mati. Hanya manusia yang masih hidup. ${ }^{36}$ Dunia ini masih berarti karena "manusia atas". Maka orang harus setia pada

31 Nietzsche memuji orang Yunani kuno karena pandangan etisnya yang menekankan pengembangan mutu yang sangat baik, dan kemuliaan dalam menghadapi nasib berbeda dengan obsesi gelap agama Yahudi-Kristen dengan dosa dan rasa bersalah. Robert C. Salomon dan Kathleen M. Higgins, Sejarah Filsafat, 423-424. 374-375.

32 Ali Mudhofir, Kamus Filsuf Barat (Yogyakarta: Pustaka Pelajar, 2001),

33 "let us say „yes"e to our desires, to our instincts, to our natural passions, to our inner needs. Let us say „yes "e to our political, economic and commercial ambitions. Let us say ,yes "e to our individual traits, to our budding genius, to our personality, to our need of self-expression.” George Thomas White Patrick, Introduction To Philosophy (London: George Allen \& Unwin Ltd, tt), 399.

${ }^{34}$ George Thomas White Patrick, Introduction To Philosophy, 114.

${ }^{35}$ Robert C. Salomon dan Kathleen M. Higgins, Sejarah Filsafat, 424.

36 Manusia yang ideal adalah manusia atas, maka pemikiran inilah yang mendorongnya pada keyakinan bahwa Tuhan (Allah) telah mati. Hanya manusia ataslah yang masih hidup. Harun Hadiwijono, Sari Sejarah Filsafat Barat 2, 129.

120 | TAJDID Vol. XVI, No. 2, Juni - Desember 2017 
dunia ini, dan tidak perlu percaya akan adanya harapan-harapan yang mengatasi dunia. ${ }^{37}$

Menurutnya, karena Tuhan sudah tidak ada, dan tidak ada dunia selain dunia yang sekarang, maka segala moral, etika dan nilai-nilai tidak mungkin bersifat transendental. ${ }^{38}$ Mustahil akan datang ke dunia ini dari suatu tempat lain di luar dunia ini sebab memang tidak ada tempat yang lain. Moral, etika dan nilai-nilai harus diciptakan oleh manusia. ${ }^{39}$ Menurutnya apabila kita dapat mengerti bahwa kita manusia inilah yang menjadi pencipta kehidupan kita sendiri, maka sadarlah kita bahwa kita bebas untuk memilih nilai-nilai apapun yang ingin kita miliki. ${ }^{40}$ Dan nilai-nilai ini yang tentu saja adalah nilai-nilai yang telah mengantar kita keluar dari kebinatangan dan membangun kebudayaan, yaitu eliminasi yang lemah oleh yang lebih kuat dalam setiap aspek kehidupan.

Menurutnya, agama Kristen dan gambarannya tentang Tuhan yang transenden, maha kuasa, maha tahu, adil dan pengasih pada dasarnya mengingkari dan menegasikan semua yang berharga di dunia ini. Agama Kristen mengklaim bahwa keebasan yang sebenarnya tercapai di dalam pengabdian kepada Tuhan, tetapi agama Kristen mengingkari kebebasan kreatif dengan menegaskan bahwa dunia dan struktur nilainya telah lengkap dan telah ditetapkan Tuhan. Agama Kristen mengklaim menawarkan kebebasan dari dosa dan kesalahan kepada manusia, tetapi hal ini dilakukan dengan mengorbankan dirinya ke dalam kehampaan yang tak berdaya dan tanpa harapan. Agama Kristen mengunggulkan doktrin cinta dan derma, tetapi ajaran ini benar-

37 Ali Mudhofir, Kamus Filsuf Barat, 375. Menurut Nietsczhe, Tuhan merupakan sesuatu hal yang terlalu rumit. Stephanus Fabijanovic, As I See Nietsczhe (Los Angeles: 109 Labor Temple, 1920), 87.

38 Transenden yakni anggapan bahwa Tuhan di luar alam. Berbeda dengan immanent yang berarti anggapan bahwa Tuhan dalam alam termasuk manusia. David Trueblood, Filsafat Agama, terj. M. Rasjidi (Jakarta: Bulan Bintang, 1965), 165.

39 Bryan Magee, The Story Of Philosophy, terj. Marcus Widodo dan Hardono Hadi, 174.

${ }^{40}$ Bryan Magee, The Story Of Philosophy, terj. Marcus Widodo dan Hardono Hadi, 174.

TAJDID Vol. XVI, No. 2, Juni - Desember $2017 \mid 121$ 
benar bersandar pada perasaan kebencian dan balas dendam yang diarahkan pada sifat kebangsawanan yang sejati. ${ }^{41}$

Untuk menjawab persoalan tersebut maka Nietzsche menegaskan bahwa Tuhan telah mati. Dengan demikian maka fondasi moralitas Kristen akan terhapuskan, sehingga orang lebih mudah untuk bergerak melampaui baik dan jahat. Dia menunjukkan pada manusia bahwa kepercayaan kepada Tuhan menyebabkan sakit dan prestasi tertinggi di dalam kehidupan manusia tergantung pada hilangnya kepercayaan ini. Dengan ini, Nietzsche berkesimpulan bahwa Tuhan tidak ada dan dari asumsi ini bergerak untuk berkonsentrasi pada tugas psikoterapi untuk membebaskan manusia dari ide bahwa mereka bergantung pada Tuhan. $^{42}$

\section{Respon Muslim terhadap Modernisme}

Sayyed Hossein Nasr pernah mengungkapan jika tidak semua muslim menerima paham modernisme tapi banyak juga muslim yang mengagumi paham modernisme ini. Nasr mengungkapkan setidaknya terdapat dua alasan dibalik perbedaan pendapat tersebut, yakni: Pertama, modernisme diterima karena banyak yang terpukau dengan istilah modern dengan makna inovatif, kreatif yang selaras dengan perjalanan waktu. kedua, penolakan atas modernisme terjadi disaat muslim menyadari ada aspek kebenaran yang hilang seperti ketidakjelasan, ketidakpastian serta ketajaman mental dan artistik yang menjadi ciri khas modernisme itu sendiri. ${ }^{43}$

${ }^{41}$ John K. Roth, "Persoalan-Persoalan filsafat agama", Kajian Pemikiran 9 Tokoh dalam Sejarah Filsafat dan Teologi, 309-310.

42 Untuk memperjelas gagasannya tentang kematian Tuhan, Nietzshe dalam salah satu karyanya membuat ilustrasi orang gila yang mondar-mandir di pasar sambil berujar, "Tidakkah kita mendengar kesibukan para penggali kubur yang sedang mengubur Tuhan? Apakah kita tidak mencium bau bangkai Tuhan? Bahkan Tuhan telah menjadi busuk dan mati. Tuhan akan tetap mati, dan kita telah membunuhnya." Friedrich Nietzshe, The Joyful Wisdom, terj. Thomas Common (London: NtN Voulis, tt), 167. John K. Roth, "Persoalan-Persoalan filsafat agama", Kajian Pemikiran 9 Tokoh dalam Sejarah Filsafat dan Teologi, 311.

43 Sayeed Hossein Nasr, "Reflection on Islam and Modern Thought" Studies in comperative Religion Vol. 15, No. 3 \& 4 (1983) : 1 .

122 | TAJDID Vol. XVI, No. 2, Juni - Desember 2017 
Nasr pun menyebut jika modernisme bertentangan dengan tradisi agama. $^{44}$

Selain ketidakjelasan dan ketidakpastian, Nasr juga menganggap, secara tradisi intelektual, modernisme menyebabkan evolusionisme, rasionalisme, eksistensialisme, agnotisisme yang hanya bisa dijawab secara intelektual sambil berharap hubungan antara syariah, ilmu pengetahuan modern dan teknologi terus terjadi. ${ }^{45}$ Nasr pun juga menegaskan jika Syariah tetaplah pijakan terapan dalam agama. Salah satu negara yang berhasil memodernisasi hukum dan tidak bertentangan dengan ketentuan agama adalah Indonesia. Pada tahun 1989, Indonesia berhasil mengakomodir hukum peradilan agama untuk urusan keagamaan. Pada 1991, Indonesia juga berhasil membuat Kompilasi Hukum Islam yang menjadi pedoman pengadilan agama. ${ }^{46}$ Martin Van Bruinessen $^{47}$ mengatakan bahwa di Indonesia telah muncul gerakan anti barat dan mengedepankan jargon Ghazwul Fikr. Dalam hal ini, Bruinessen mengindikasikan bahwa jargon tersebut memiliki tendensi arabisasi yang secara ideologi cukup bertentangan dengan ideologi yang diusung para modernis. Bruinessen juga mengungkapkan jika konflik yang terjadi di Timur tengah memiliki dampak ke Indonesia yang bermayoritas muslim. Menariknya, banyak para akademisi memilih untuk meneruskan studi keislamannya di barat. terhitung sejak era Soeharto, ${ }^{48}$ keran beasiswa ke Barat sangat terbuka bagi para mahasiswa asal Indonesia. Sedangkan, peminat studi keislaman ke Timur tengah

${ }^{44}$ Sayeed Hossein Nasr, "Reflection on Islam and Modern Thought" : 2.

${ }^{45}$ Sayeed Hossein Nasr, "Reflection on Islam and Modern Thought" : 13.

46 Euis Nurlaelawati, Modernizaton, Tradition And Identity: The Kompilasi Hukum Islam And Legal Practice In The Indonesian Religious Court (Amsterdam: Amsterdam University Press, 2010), 16-17.

47 Martin Van Bruinessen, "Islam and Development in Southeast Asia: Southeast Asian Muslim Responses to Globalization" JICA Research Insitute, Singapore (2009) : 1 .

48 Martin Van Bruinessen, "Islam and Development in Southeast Asia: Southeast Asian Muslim Responses to Globalization" : $2-5$.

TAJDID Vol. XVI, No. 2, Juni - Desember 2017 |123 
asal Indonesia berangkat dari lembaga-lembaga seperti Dewan Dakwah Islam Indonesia (DDII) dan lain sebagainya. ${ }^{49}$

Ketegangan muslim dalam menolak ataupun menerima modernisme memuncak dalam tulisan Hossein Aghababa yang berjudul Modern Islam versus Islamic Modernity. Aghababa menilai, secara historis, hubungan antara Islam dan modernitas tidak pernah berjalan dengan baik dan tanpa rintangan. ${ }^{50}$ Satu-satunya titik temu yang mungkin terjadi antara Islam dan modernisme adalah penggunaan istilah modern Islam bukan sebaliknya. hal ini disebabkan, Islam telah mengklaim sebagai modern itu sendiri. Islam merupakan agama yang memberikan tawaran baru berbasis kemaslahatan dan kebaikan dan menciptakan keseimbangan. Bagi Aghababa, salah satu bentuk modernisasi Islam adalah eksistensi sikap toleransi di tengah masyarakat. Bentuk lain dari modernisasi Islam adalah eksistensi toleransi antar madzhab keislaman. ${ }^{5153}$ Dalam analisa terakhirnya, Aghababa menyebut peluang dialog antara Islam dan barat masih diharapkan terutama yang melibatkan beberapa elemen masyarakat. pola masyrakat modern yang sangat melekat seperti HAM, Hak wanita juga perlu dijaga karena simbolsimbol tersebut, sewaktu-waktu, lebih penting ketimbang urusan tentang idealisme konsep yang ada di setiap agama-agama. ${ }^{5254}$

\section{Islam Wasatiyah: Moderasi ala Islam}

Sebagaimana disampaikan sebelumnya, upaya modernisasi yang terjadi di Indonesia memberikan warna tersendiri bagi Islam di dunia. Pengaruh konflik timur tengah yang mempengaruhi dunia Islam, ${ }^{53}$ dalam kaca mata positif, memberikan peluang bagi Indonesia memunculkan corak pemikiran Islam yang modern dan toleran terhadap perbedaan. Secara definitif, istilah yang

${ }^{49}$ Martin Van Bruinessen, "Islam and Development in Southeast Asia: Southeast Asian Muslim Responses to Globalization" : 5-7.

50 Hossein Aghababa, "Modern Islam versus Islamic Modernity" $2^{\text {nd }}$ International Conference on Humanities, Historical and Social Sciences IPEDR Vol. 17 (2011) : 25 .

${ }^{51}$ Hossein Aghababa, "Modern Islam versus islamic Modernity" : 27-28.

52 Hossein Aghababa, "Modern Islam versus islamic Modernity" : 29.

53 Martin Van Bruinessen, "Islam and Development in Southeast Asia: Southeast Asian Muslim Responses to Globalization" : 2-5.

124 | TAJDID vol. XVI, No. 2, Juni - Desember 2017 
diungkapkan oleh beberapa pemikir Islam di Indonesia menyebut dengan Islam moderat atau Islam wasatiyyah. Para pemikir Indonesia merujuk Islam wasatiyah dari surat Al-Baqarah ayat 143 yang berbunyi:

Artinya: "dan demikian (pula) Kami telah menjadikan kamu (umat Islam), umat yang adil dan pilihan[95] agar kamu menjadi saksi atas (perbuatan) manusia dan agar Rasul (Muhammad) menjadi saksi atas (perbuatan) kamu. Dan Kami tidak menetapkan kiblat yang menjadi kiblatmu (sekarang) melainkan agar Kami mengetahui (supaya nyata) siapa yang mengikuti Rasul dan siapa yang membelot. dan sungguh (pemindahan kiblat) itu terasa Amat berat, kecuali bagi orangorang yang telah diberi petunjuk oleh Allah; dan Allah tidak akan menyia-nyiakan imanmu. Sesungguhnya Allah Maha Pengasih lagi Maha Penyayang kepada manusia."

Wasatiyah merupakan satu konsep yang berasal dari epistemologi Islam. Wasatiyyah diartikan sebagai penengah diantara dua hal yang salin berhadapan. Salah satu negara yang telah menerapkan Wasatiyyah adalah Malaysia. Secara konseptual, Wasatiyyah difungsikan sebagai bentuk ,perlawanan terhadap ekstermisme. ${ }^{54}$ Menurut Abdullah MD Zin, wasatiyyah dapat diartikan sebagai keadilan dan keseimbangan, tidak ketat dan tidak longgar. ${ }^{55}$ Artinya, wasatiyyah diposisikan sebagai penengah dari dua perkara yang memiliki perbedaan satu sama lain tanpa memperlihatkan kecondongan ke satu pihak manapun.

Sebagai penunjang peradaban Islam, Wasatiyyah memosisikan dirinya sebagai bentuk keseriusan, ketersinambungan dengan penuh komitmen untuk memperoleh hasil yang maksimal tanpa memisahkan antara agama dan tugas negara. ${ }^{56}$ Secara teknis,

${ }^{54}$ Mohd Shukri Hanapi, "The Wasatiyyah (Moderation) Concept in Islamic Epistemology: A case study of its implementation in Malaysia" Interntional Journal of Humanities and social science, Vol. 4, No. 9 (2014) : 51.

55 Abdullah MD Zin, Pendekatan Wasatiyyah: Definisi, Konsep dan Pelaksanaan (Putrajaya: Institut Wasatiyyah Malaysia, 2013), 14-15.

56 Mohd Yusof Hj Othman dkk, "Wasatiyyah: The Way Forward for Islamic hadhari” ICIAS (2014) : 31.

TAJDID Vol. XVI, No. 2, Juni - Desember $2017 \mid 125$ 
konstruksi konsep wasatiyyah ${ }^{57}$ terfokus dalam beberapa hal, seperti: (1) Pemerintahan yang baik berdsarkan prinsip-prinsip Islam dan demokratik; (2) Antoposentris dan petumbuhan ekonomi inklusif berdasarkan pada prinsip-prinsip ekonomi Islam; (3) Kepemimpinan dengan integritas moral yang tinggi; membawa perdamaian, keharmonisan dan kolaborasi dengan kalangan non muslim; (5) Perbaikan pendidikan yang holistik; (6) Kesadaran untuk membangun mental para pemuda muslim; dan (7) keseimbangan dan sinergi antara tradisi agama Islam, santifik dan proses teknologi.

Sedangkan menurut Mohd Shukri Hanapi, ${ }^{58}$ konsep Wasatiyyah tediri dari beberapa hal, yakni: (1) Wasatiyyah pada aspek kebebasan beragama; (2) Al-Wasatiyyah dalam pendisitribusian harta; (3) Al-Wasatiyyah dalam hal distribusi kekuatan politik; (4) Al-Wasatiyyah dalam penggunaan bahasa; dan (5) Al-Wasatiyyah dalam pendidikan.

\section{Kesimpulan}

Jika menelisik dari pembahsan yang sudah terpapar diatas, perlu disimpulkan beberapa poin yaitu: Modernisasi yang dipahami oleh Fazlur Rahman dalam bukunya Islam and Modernity tidak sepenuhnya diterima baik oleh muslim. Mereka yang kontra terhadap pendapat Fazlur Rahman mencoba menengahi antara Islam dan modernitas itu sendiri. Terlebih, Friedrich Nietzche yang memproklamirkan sebagai ateis dengan menyebut tuhan telah mati membuktikan ada permasalahan yang terdapat dalam epistemologi modern. Maka munculah dua opsi untuk menengahi keduanya: Moderasi Islam atau Islam moderat.

Bagi negara-negara di Asia tenggara, Indonesia-Malaysia telah memprioritaskan Islam wasatiyyah sebagai acuan ditengah masalah terorisme yang ada saat ini, konsep wasatiyyah memberikan untuk

${ }^{57}$ M. Kamal Hassan, "Reconstruction of Wasatiyyah Based on Muslim Civilization in Asian Region" Iternational Conference on Empowering Islamic Civilization (2015) : 17.

58 Mohd Shukri Hanapi, “The Wasatiyyah (Moderation) Concept in Islamic Epistemology: A case study of its implementation in Malaysia” : -56 60.

126 | TAJDID Vol. XVI, No. 2, Juni - Desember 2017 
berada di tengah ditengah 2 hal yang mungkin bertentangan. Selain itu, konsep Wasatiyyah juga memberikan opsi kepada sebuah negara untuk ,memfasilitasiee dan menjembatani hubungan agama dan negara.

\section{Daftar Pustaka}

Aghababa, Hossein. "Modern Islam versus Islamic Modernity" $2^{\text {nd }}$ International Conference on Humanities, Historical and Social Sciences IPEDR Vol. 17 (2011)

Borchert, Donald M. dkk, Encyclopedia Of Philosopby (Farmington Hills: Thomson Gale, 2006)

David Trueblood, Filsafat Agama, terj. M. Rasjidi (Jakarta: Bulan Bintang, 1965)

Fabijanovic, Stephanus. As I See Nietsçhe (Los Angeles: 109 Labor Temple, 1920)

Gellner, Ernest. Postmodernism, Reason \& Religion (London: Routledge, 1992),

Hadiwijono, Harun. Sari Sejarah Filsafat Barat 2

(Yogyakarta: Kanisius, 1980)

Hanapi, Mohd Shukri. "The Wasatiyyah (Moderation)

Concept in Islamic Epistemology: A case study of its implementation in Malaysia" Interntional Journal of Humanities and social science, Vol. 4, No. 9 (2014)

Hardiman, F. Budi. Filsafat Modern:Dari Machiavelli samapai Nietasche (Jakarta: Gramedia Pustaka Utama, 2007)

Hassan, M. Kamal. "Reconstruction of Wasatiyyah Based on

Muslim Civilization in Asian Region" Iternational Conference on

Empowering Islamic Civilization (2015)

Higgins, Robert C. Salomon dan Kathleen M. Sejarah Filsafat, terj.

Saut Pasaribu (Yogyakarta: Bentang Budaya, 2003) cet ke-2

Hj Othman, Mohd Yusof dkk, "Wasatiyyah: The Way Forward for Islamic hadhari" ICIAS (2014)

Kajian Pemikiran 9 Tokoh dalam Sejarah Filsafat dan Teologi, terj. Ali

Noer Zaman (Yogyakarta: Pustaka Pelajar, 2003)

Magee, Bryan. The Story Of Philosophy, terj. Marcus Widodo dan

Hardono Hadi (Yogyakarta: Kanisius, 2008)

MD Zin, Abdullah. Pendekatan Wasatiyyah: Definisi, Konsep dan Pelaksanaan (Putrajaya: Institut Wasatiyyah Malaysia, 2013)

TAJDID Vol. XVI, No. 2, Juni - Desember 2017 |127 
Mudhofir, Ali. Kamus Filsuf Barat (Yogyakarta: Pustaka Pelajar, 2001),

Muhadjir, Noeng. Metode Penelitian Kualitatif (Yogyakarta: Rake Sarasin, 2000):

Munir, Misnal. Aliran-Aliran Utama Filsafat Barat Kontemporer (Yogyakarta: Penerbit Lima, 2008)

Muslih, Muhammad. Filsafat ilmu: Kajian atas asumsi dasar paradigma dan kerangka teori ilmu pengetabuan (Yogyakarta: Penerbit Belukar, 2006) cet. ke-3,

Nasr, Sayeed Hossein. "Reflection on Islam and Modern Thought" Studies in comperative Religion Vol. 15, No. 3 \& 4 (1983)

Nietzshe, Friedrich. The Joyful Wisdom, terj. Thomas Common (London: NtN Voulis, $\mathrm{tt}$ ),

Nurlaelawati, Euis. Modernizaton, Tradition And Identity: The Kompilasi Hukum Islam And Legal Practice In The

Indonesian Religious Court (Amsterdam: Amsterdam University Press, 2010)

Patrick, George Thomas White. Introduction To Philosophy (London:

George Allen \& Unwin Ltd, $\mathrm{tt}$ )

Rahman, Fazlur. Islam and modernity: transformation of an Intellectual tradition (London: The University of Chicago press, 1919),

Robinson, Dave. Nietasche and Postmodernism (London: Cox \& Wyman Ltd., 1999)

Russel, Bertrand. Sejarah Filsafat Barat, terj. Sigit Jatmiko dkk (Yogyakarta: Pustaka Pelajar, 2007) cet. ke-3

Stuart SIM, The Routledge Companion to Postmodernism (London: Routledge, 2001)

Van Bruinessen, Martin. "Islam and Development in Southeast Asia: Southeast Asian Muslim Responses to Globalization" JICA Research Insitute, Singapore (2009)

Waugh, Patricia. Postmodernism (USA: Routledge, Chapman and Hall, 1992),

Zarkasyi, Amal Fathullah. "Tajdid dan Modernisasi Pemikiran Islam", Tsaqafah vol. 9, No. 2 (2013) 